\section{Germany revamps system to fund medical research}

Munich. German research minister Matthias Wissmann last week announced a major restructuring of medical research funding that for the first time establishes independent external refereeing for projects in universities and their associated clinics.
A new plan for German health research

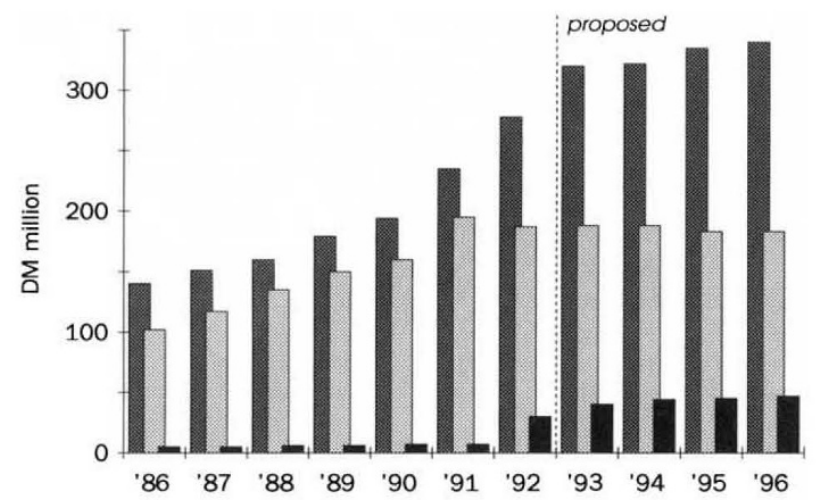

tend to be small and isolated, shunning collaborative links with other small groups, either locally or nationally.

Wissmann wants to change this. The BMFT is allocating DM250 million over the next eight years to support six to eight interdisciplinary research centres. These centres will be composed of several research teams, usually local, that focus on defined collaborative projects. The projects undertaken by the centres will be assessed by a formal refereeing systems of international standards.

Most of the cost will at first be picked up at the federal level, but the BMFT will gradually reduce its share of financial support over the eight years. The clinics will have to make up the difference with funds from the Länder, thereby ensuring that the money is used for research centres Project money Other institutiona research

\section{Whaling meeting expected to leave issue unresolved}

Tokyo. Despite years of debate and scientific analysis, next week's meeting of the International Whaling Commission (IWC) is unlikely to resolve the fate of commercial whaling.

Anti-whaling forces at the annual meeting in Kyoto do not have sufficient support for a French proposal to create a whale sanctuary in the southern ocean which would prevent the Japanese from resuming commercial whaling. Neither does Japan have the votes to achieve a resumption in commercial whaling, despite evidence from the IWC's scientific committee that there are sufficient numbers of minke whales.

In 1982, the IWC introduced a moratorium on commercial whaling on the basis of incomplete data on the size of the population and whether it was sufficient to sustain commercial activity without risk to the species. By 1991, the IWC scientific committee had developed a revised management procedure (RMP) to provide adequate safeguards and had estimated the population of Antarctic minke whale at 760,000 , well above the number needed to resume commercial whaling (see Nature 357, 532; 1992). But the IWC has yet to decide whether to continue or end the moratorium, preferring to ask more questions of the scientific committee regarding the management procedure (see Nature 358, 99; 1992).

"My guess is the commissioners will be desperate for a reason to postpone a decision", says one scientist participating in the closed scientific committee meetings that have preceded next week's plenary session. "If they voted to lift the moratorium, they'd get lynched at home."

A proposal by France to create a whale sanctuary in the southern ocean below $40^{\circ} \mathrm{S}$ may provide grounds for delay. The Japanese are confident they can muster the necessary 25 per cent minority to block the French proposal if a vote is called. Instead, those against whaling are likely to push for further discussion of the proposal.

The Japanese are in no hurry to push for resumption of commercial whaling. "Even if the IWC permits us to resume, commercial whaling [in the Antarctic] has died", says Japan's IWC representative, Fukuzo Nagasaki. "It would take two or three years to develop a concrete plan."

Japan sees its fight to preserve commercial whaling as a test case for its exploitation of other commercially more important marine resources, for example the bluefin tuna in the Atlantic. A defeat in a situation where sustainable management of the resource seems possible could threaten other resources where there is greater cause for concern about depletion.

David Swinbanks compounded by the fact that research groups 